\title{
Sobre o centro, a crítica e a busca da liberdade na práxis acadêmica
}

\author{
Maria Ceci Misoczky*
}

\begin{abstract}
Resumo
Este artigo tem origem nas discussões que antecederam e que foram travadas durante 0 "IV Encontro de Estudos Organizacionais" (Eneo), evento organizado em torno de uma chamada de trabalhos com um tema definido: "apropriando teoria e prática - deslocando o centro".

Apesar do aparente consenso em torno desse tema, os acontecimentos evidenciaram uma importante diversidade de entendimentos. Para avançar nesse debate, precisamos de algumas categorias de compreensão que permitam uma reflexão crítica sobre nosso fazer acadêmico, que estabeleçam um vocabulário para o debate e que nos possibilitem pensar outras práticas. Nesse sentido, nos itens que seguem, após esclarecer a relação com textos e autores - a partir da desconstrução inspirada em Derrida -, apresento algumas categorias que podem nos apoiar na reflexão: modernidade e transmodernidade, colonialidade do saber e do ser, conhecimento e geopolítica e pensamento de fronteira. Feito isso, desenvolvo algumas idéias sobre 0 significado e as possibilidades do fazer acadêmico em tempos de globalização, considerando sempre o fenômeno da colonialidade e insistindo na possibilidade de enfrentá-lo. No final deste texto, encontra-se transcrita a apresentação que fiz na sessão de encerramento do "IV Eneo".
\end{abstract}

Palavras- chave: colonialidade do saber; transmodernidade; apropriar teoria e prática.

\begin{abstract}
This article has its origin in the debates that anticipated and that happened during the IVth Meeting of Organizational Studies. This event was organized based in a call for papers with the issue: appropriating theory and practice - delocating the center. Despite the apparent consensus around this issue, the events revealed an important diversity of understandings. In order to advance in the debate we need some categories of understanding that allow the critical reflection on our academic making, that help us to have a vocabulary for the debate and that allow us to think about our practice. In that sense, after establishing the relation between texts and authors from a Derridean inspired deconstructionism, I present some categories that can support our reflection modernity and trans-modernity; coloniality of knowledge and of the being, knowledge and geopolitics; border thinking. After that I develop some ideas on the meaning and the possibilities of the academic making in times of globalization, considering always the phenomenon of coloniality and insisting in the possibility of confronting it. At the end of the text there is the transcription of the presentation I made at the closing session of the IVth Meeting on Organization Studies.
\end{abstract}

\section{Introdução}

Este artigo tem sua origem nas discussões que antecederam e que foram travadas durante o "IV Encontro de Estudos Organizacionais" (Eneo). Esse evento foi organizado em torno de uma chamada de trabalhos com um tema definido: "apropriando teoria e prática - deslocando o centro".

Apesar do aparente consenso em torno do tema, os acontecimentos evidenciaram uma importante diversidade de entendimentos. Aproveito esse espaço propiciado pela revista Cadernos Ebape.BR para esclarecer minha visão sobre o mesmo. Esse é um artigo assinado e, nesse sentido, expressa uma posição que, mesmo

Doutora em Administração. Mestre em planejamento urbano regional. Docente da Escola de Administração/PPGA/UFRGS. Endereço: Escola de Administração/UFRGS. Washington Luis, 855 - Porto Alegre - RS - CEP 90010-460. E- mail: mcaraujo@ ea.ufrgs.br. 
compartilhada por uma comunidade de pesquisadores, na forma como está formulada aqui é de minha exclusiva responsabilidade. Além do mais, não se trata de um texto conclusivo; em vez disso, o propósito é circular idéias e desacomodar certezas.

Para avançar nesse debate precisamos de algumas categorias de compreensão que permitam refletir criticamente sobre nosso fazer acadêmico, que estabeleçam um vocabulário para o debate e que nos possibilitem pensar outras práticas. Desse modo, nos itens que seguem, após esclarecer a relação com textos e autores a partir da desconstrução inspirada em Derrida, apresento algumas categorias que podem nos apoiar na reflexão: modernidade e transmodernidade, colonialidade do saber e do ser, conhecimento e geopolítica e pensamento de fronteira. Feito isso, desenvolvo algumas idéias sobre o significado e as possibilidades do fazer acadêmico em tempos de globalização, considerando sempre o fenômeno da colonialidade e insistindo na possibilidade de enfrentá-lo.

No final desse texto se encontra a transcrição da apresentação que fiz na sessão de encerramento do "IV Eneo". Optei por deixá-la na íntegra e no formato original, para preservar o tom do momento. Como foi um texto preparado para uma exposição verbal, não tomei os cuidados necessários com referências aos autores que o inspiraram. Tentei compensar acrescentando referências no final desse artigo. Peço desculpas aos autores por alguma omissão.

\section{Pensar, imaginar, argumentar...}

Brasileiros e latino-americanos fazemos constantemente a experiência do caráter postiço, inautêntico, imitado da vida cultural que levamos. (SCHWARZ, 1987, p.30)

Esse texto constitui mais um esforço para problematizar os condicionamentos que nos induzem à cópia e à subordinação, afirmando, desde logo, que não se trabalha com qualquer tipo de simplificação das relações transnacionais no processo de globalização, nem a partir de qualquer posição de nacionalismo ingênuo ou de isolamento, ao mesmo tempo em que se busca questionar a mitificação do estrangeiro metropolitano e a produção acadêmica reflexa. $\mathrm{O}$ que se propõe é a possibilidade de dialogar com a herança do conhecimento moderno sem subalternidade e sem a melancolia de um certo exílio do centro dito civilizado. ${ }^{1}$

Além da cópia, sofremos com outro fenômeno. Graças ao sentimento de contradição entre a realidade nacional e o prestígio ideológico dos países que nos servem de modelo, vivemos um intenso esforço de atualização e "desprovincianização" da nossa produção acadêmica.

Tem sido observado que a cada geração, a vida intelectual no Brasil parece recomeçar do zero. $O$ apetite pela produção recente dos países avançados, muitas vezes, tem como avesso o desinteresse pelo trabalho da geração anterior e a conseqüente descontinuidade da reflexão. Conforme notava Machado de Assis em 1878: "o influxo externo é o que determina a direção do movimento". (SCHWARZ, 1987, p.30)

Em sentido oposto, os artigos que seguem são exemplos importantes de construção de conexões e de esforços de atualização da nossa tradição intelectual.

Falta ainda mencionar que, como parte desse fenômeno, há uma ausência de relação das teorias com o movimento social conjunto, o que, ao fim e ao cabo, compromete "a relevância do próprio trabalho e dos assuntos estudados". Não se trata de defender a continuidade pela continuidade, mas a "constituição de um campo de problemas reais, particulares, com inserção e duração histórica próprias, que recolha as forças em

\footnotetext{
${ }^{1}$ Como exemplo desse procedimento, podemos considerar Philosophy in Latin América in the twentieth century, onde Enrique Dussel analisa os problemas centrais e os principais filósofos de cada corrente filosófica latino-americana, finalizando com uma bibliografia indicativa, organizada por país de origem. Segrera (2000), por sua vez, revisa autores e enfoques latino-americanos no âmbito das ciências sociais.
} 
presença e solicite um passo adiante". Para que isso venha a ocorrer é, sem dúvida, indispensável compreendermos que não basta reproduzir as tendências metropolitanas para alcançar uma vida intelectual mais substantiva (SCHWARZ, 1987, p.31).

Nestes itens, apresentamos algumas categorias teóricas, desenvolvendo alguns argumentos que nos permitam imaginar saídas para essa situação.

\section{A positividade da desconstrução e a possibilidade da transmodernidade}

Um equívoco usual cometido contra Derrida é tratar a desconstrução como uma crítica ou, pelo menos, como uma ação estratégica de oposição. Uma leitura da desconstrução como negatividade ignora os esforços de Derrida (1995, p.88) para apresentá-la como tendo um caráter afirmativo.

A desconstrução não é negativa, apesar de ter sido interpretada assim e de todos os tipos de alerta que dei. Para mim, ela sempre acompanha uma exigência afirmativa. Eu diria que ela nunca acontece sem amor.

Dessa relação positiva no encontro com os textos, surge a abertura para as possibilidades de futuros alternativos. A atitude em relação aos textos proposta por Derrida é sempre a de transformações ativas, nunca de reflexão passiva ou de interpretação sem desafios.

Saramago (2004, p.71) indica que o foco da ética da leitura em Derrida

não se direciona apenas para o texto, mas busca, a partir da situação da leitura, estender suas premissas a todo outro; ou seja, do ponto de vista da desconstrução, tal ética consideraria a relação com o texto como sendo sempre uma relação paradigmática com todo e qualquer outro.

Os aspectos éticos da leitura se referem, assim, a pensar a leitura como herança e como a "busca da justa medida de liberdade que se poderia ter diante de um texto". Nessa busca, que se realiza no contexto da imposição de um legado heterogêneo e contraditório, "o conceito de inventividade assume um papel decisivo, pois é sobre ela que recai o peso da autêntica responsabilidade.” (SARAMAGO, 2004, p.77).

Uma herança não se junta nunca, ela não é mais uma consigo mesma. Sua unidade presumida, se existe, não pode consistir senão na injunção de reafirmar escolhendo. É preciso filtrar, peneirar, criticar; é preciso escolher entre vários possíveis que habitam uma mesma injunção. E habitam-na de modo contraditório, em torno de um segredo. Se a legibilidade de um legado fosse dada, natural, transparente, unívoca, se ela não pedisse e não desafiasse ao mesmo tempo a interpretação, não se teria nunca o que herdar. Seríamos afetados por isso como por uma causa - natural ou genética. [...] A injunção (escolhe e decide o que herdas, dirá ela sempre) não pode ser uma, a não ser dividindo-se, rasgando-se, diferindo de si mesma, falando a cada vez diversas vozes - e com diversas vozes. (DERRIDA, 1994, p.33)

Um dos sentidos para différer em Derrida (1971) é exatamente ser outro, não ser o mesmo, ser diferente, ser dessemelhante. Na língua francesa, há o différent (indicando a alteridade como dessemelhança) e há o différend (como polêmica, divergência, dissensão). No regime da différence, um elemento só ganha existência na perspectiva de outro que o antecede e de um terceiro que o sucede (NASCIMENTO, 2004). Desse modo, coloca-se uma série de paradoxos que correspondem a uma necessidade histórica - é preciso sair, mas a saída é impossível; é impossível sair, mas se sai sempre parcialmente, se está simultaneamente dentro e fora. Essa abertura de possibilidades de saída só é concretizada pelo caráter público da escrita, como a instalação de um debate. Essa busca de abertura só faz sentido, ainda, como parte do quadro geral de uma época - a modernidade (MIRANDA, 1986).

É preciso, também, reconhecer que a busca de abertura sempre é contida pela linguagem. O paradoxo da linguagem nos leva a enfrentar o problema de que mesmo quando queremos nos colocar em oposição a algo, compartilhamos a mesma linguagem, a linguagem que queremos superar. Não há resposta metodológica ou 
epistemológica para esse paradoxo, em Derrida encontramos apenas - e isso já é muito - a esperança de que sejamos capazes de encontrar saídas para esses limites.

Dussel (2002), com a categoria de transmodernidade, desenvolve uma possibilidade de saída. Sem deixar de reconhecer a presença da modernidade, Dussel (2006, p.505) afirma que os problemas de pobreza, injustiça e exclusão presentes em todo o planeta são o outro lado da moeda dos grandes lucros e da concentração de poder. Essa contradição é também uma expressão do

confronto entre o mundo eurocêntrico, ${ }^{2}$ exclusivo e violento, e a possibilidade de uma modernidade diferente. Esta seria transversal e permitiria a reinvenção da forma social do planeta. A esse novo tipo de possibilidade teórica, eu denomino transmoderna; uma utopia futura não dominada pela modernidade, mas em constante diálogo com ela. O objetivo é construir um pluriverso (não um universo) em que cada cultura possa conservar sua própria identidade e, ao mesmo tempo, assimilar os desenvolvimentos dessa modernidade globalizante. (DUSSEL, 2006, p.505)

A transmodernidade funcionaria como meio de localização e de encontro de nós mesmos, a partir da categoria da exterioridade. Exterioridade, nas formulações de Dussel (2002), não se refere a estar fora, a não ser tocado pela modernidade; refere-se a um estar fora que é precisamente constituído como diferença em relação a um discurso hegemônico.

\section{A transmodernidade como projeto de superação da colonialidade}

Um dos primeiros registros sobre o problema da colonialidade se encontra num artigo de Quijano (1993), publicado no contexto dos debates sobre os 500 anos da conquista européia da América. Diz ele que colonialidade é um neologismo que tem, com relação ao termo colonialismo, a mesma ligação que modernidade em relação ao termo modernismo. A colonialidade do poder se refere ao prolongamento contemporâneo das bases coloniais que sustentaram a formação da ordem capitalista. Ainda que o colonialismo político tenha sido eliminado, a relação entre a cultura européia (ou ocidental) e as outras continua sendo uma relação de dominação colonial (Quijano, 1992). Portanto, a colonialidade não pode ser pensada fora do contexto da hegemonia de padrões eurocêntricos de conhecimento, com sua pretensão de universalidade e de produção da verdade; não pode ser pensada fora de uma reflexão sobre a modernidade.

Do ponto de vista da história oficial,

a modernidade tem origens identificáveis no tempo e no espaço: no norte da Europa (especialmente na França, na Alemanha e na Inglaterra) no século XVII, em torno dos processos da Reforma, do Iluminismo e da Revolução Francesa. Esses processos se cristalizaram no final do século XVIII (a moderna epistema de Foucault) e se consolidaram com a Revolução Industrial (ESCOBAR, 2002, p.3).

Segundo Mignolo (2001), um dos modos mais efetivos de evitar questionamentos sobre o papel da experiência colonial na modernidade reside em apresentar o final do século XVIII como o marco da modernidade.

Já do ponto de vista da colonialidade, é impossível separar as origens da modernidade da conquista da América e do controle do oceano Atlântico após 1492; bem como da exploração econômica de nossos recursos naturais, produzindo a acumulação primitiva que levou eventualmente à formação do capitalismo (DUSSEL, 2002).

\footnotetext{
${ }^{2}$ A categoria do eurocentrismo é central nesta reflexão. Para Aníbal Quíjano, segundo Teves (2002), o eurocentrismo se refere a um modo de compreender e interpretar as diversas experiências históricas das sociedades não-européias de acordo com as características e trajetórias particulares da história européia, as quais são convertidas, desse modo, em modelo de interpretação de alcance e validade universais. Eurocentrismo é entendido não como fenômeno que se desenvolveu apenas no centro europeu ou nos EUA, mas como algo que envolveu além das nações com vocação imperial, como Austrália e Nova Zelândia, por exemplo, regiões do planeta como países africanos, asiáticos e latino-americanos, através das elites locais. Além disso, é óbvio que nos dias de hoje, além do eurocentrismo, temos um americanocentrismo (DUSSEL, 2006).
} 
Dussel (2002) identifica dois paradigmas da modernidade. O primeiro, a partir de um horizonte eurocêntrico, propõe que esse fenômeno é exclusivamente europeu; o segundo, o da transmodernidade, concebe a modernidade européia como uma parte, ainda que central, do sistema mundo.

Segundo este paradigma, a Europa tivera características excepcionais internas que permitiram que ela superasse, essencialmente por sua racionalidade, todas as outras culturas. Filosoficamente, ninguém como Hegel expõe essa tese da modernidade: o espírito germânico é o espírito do Novo Mundo, cujo fim é a realização da Verdade absoluta, como autodeterminação infinita da Liberdade, que tem por conteúdo sua própria forma absoluta. O que chama a atenção é que o espírito da Europa (germânico) é a verdade absoluta que se determina ou se realiza por si mesma, sem dever nada a ninguém. Essa tese [...] é a que se impõe não só na Europa ou nos Estados Unidos, mas também em todo o mundo intelectual da periferia mundial.

[...] uma segunda posição, a partir da periferia, considera o processo de modernidade como a "gestão" racional do sistema mundo. Essa posição tenta recuperar o recuperável da modernidade e negar a dominação e exclusão do sistema-mundo. É, então, um projeto de libertação da periferia negada desde a origem da modernidade. O problema não é a mera superação da razão instrumental (como para Habermas) ou da razão terror dos pós-modernos, mas a superação do próprio sistema mundo tal como foi desenvolvido, até hoje, durante 500 anos. [...] a modernidade seria, para o paradigma mundial, um fenômeno próprio do "sistema" como "centro e periferia". Essa simples hipótese muda absolutamente o conceito de modernidade, sua origem, desenvolvimento e crise atual; e, por isso, também o conteúdo da modernidade tardia. (DUSSEL, 2002, p.51-52, p.65)

Em outras palavras, o eurocentrismo da modernidade reside exatamente em haver confundido a universalidade abstrata com a mundialidade concreta. Para tanto, bem como para justificar a práxis irracional da violência, é preciso construir um mito, que pode ser descrito assim (DUSSEL, 2000, p.251):

1) a civilização moderna se julga mais desenvolvida, superior (o que significará sustentar sem concorrência uma posição ideologicamente eurocêntrica);

2) a superioridade a obriga a desenvolver os mais primitivos, rudes, bárbaros, como uma exigência moral;

3) o caminho de tal processo educativo de desenvolvimento deve ser seguido pela Europa (é, de fato, um desenvolvimento unilinear e à européia, o que determina, novamente, sem consciência alguma, a "falácia desenvolvimentista");

4) como o bárbaro se opõe ao processo civilizador, a práxis moderna deve exercer, em último caso, a violência que for necessária para eliminar os obstáculos a tal modernização (a guerra justa colonial);

5) essa dominação produz vítimas (de muitas formas), violência que é interpretada como um ato inevitável e com sentido quase ritual de sacrifício; o herói civilizador incute nas suas vítimas a idéia do holocausto como um sacrifício salvador (o índio colonizado, o escravo africano, a mulher, a destruição ecológica da Terra etc.);

6) para ser moderno, o bárbaro tem uma "culpa" (o opor-se ao processo civilizatório) que permite à modernidade apresentar-se como "emancipadora" da "culpa" de suas próprias vítimas;

7) por último, e pelo caráter civilizatório da modernidade, são interpretados como inevitáveis o sofrimento ou os sacrifícios (os custos) da modernização de outros povos tidos como atrasados (imaturos), de outras raças escravizadas, do outro sexo por ser tido como fraco, etc...

Por tudo isso, caso se pretenda a superação da modernidade, será necessário refutar a negação do mito da modernidade. Para isso, o "outro-rosto", negado e vitimado, deve primeiro de tudo descobrir-se como "inocente": é a vítima "inocente" do sacrifício ritual, que ao descobrir-se inocente julga a modernidade culpada da violência sacrificadora, conquistadora, constitutiva e essencial. Ao negar a inocência da modernidade e ao 
afirmar a alteridade do "Outro", negado antes como vítima culpada, permite-se "des-cobrir" pela primeira vez o "Outro rosto", oculto e essencial da modernidade: o mundo periférico colonial, o índio sacrificado, o negro escravizado, a mulher oprimida, a criança e a cultura popular alienados etc., como vítimas de um ato irracional (como contradição do ideal racional da própria modernidade).

Como indica Mignolo (2003), a colonialidade do poder abre uma porta analítica e crítica que revela o lado negro da modernidade e o fato de que nunca houve, nem pode haver, modernidade sem colonialidade. A existência da colonialidade do poder e da conseqüente colonialidade do saber, indica como articulação resultante, a existência da colonialidade do Ser. Maldonado-Torres (2004, p.42) desenvolve essa concepção a partir de Heidegger e Gadamer:

[...] em vez da historicidade e da tradição, o que melhor explicaria a revelação do Ser e a colonialidade do Ser seria a diferença colonial e a lógica da colonialidade. Sugiro que o Ser está para a história e para a tradição, assim como a colonialidade do Ser está para a colonialidade do poder e para a diferença colonial. A colonialidade do Ser se refere, portanto, ao processo através do qual o senso comum e a tradição são marcados por dinâmicas de poder que têm um caráter preferencial: elas discriminam pessoas e marcam comunidades.

A crítica radical envolve, então, não apenas levar em conta as nossas raízes, mas também subordiná-las ao projeto crítico dos marcos que mantêm viva a topologia dominante do Ser e a geopolítica racista do conhecimento. Trata-se, também, de examinar nossa cumplicidade com antigos padrões de dominação e buscar as faces invisíveis com as quais podemos aprender (MALDONADO-TORRES, 2004).

Nesse sentido, a esperança da transmodernidade só pode se concretizar como mútua fecundidade criadora da modernidade e de sua alteridade negada. O projeto transmoderno é uma co-realização de solidariedade. Não se trata de um projeto pré-moderno - como afirmação folclórica do passado -, nem de um projeto antimoderno de grupos conservadores e nem de um projeto pós-moderno de negação da modernidade, como crítica de toda razão. Deve ser um projeto transmoderno, por subsunção real do caráter emancipador racional da modernidade e de sua alteridade negada, por negação de seu caráter mítico e pelo deslocamento da modernidade de seu centro europeu para um horizonte mundial (DUSSEL, 2000).

No plano da produção de conhecimento, a noção de colonialidade do saber indica a busca de formas distintas de conhecer - produzidas em espaços de liberdade resgatados da dominação das heranças do eurocentrismo -, implicando uma profunda descolonização epistêmica de nossos modos de elaborar sentidos e de nos reconhecer no mundo (TEVES, 2002). Mignolo (2001) propõe a idéia de pensamento de fronteira, para localizar exatamente os limites da filosofia e das ciências sociais ocidentais com relação ao espaço onde emergem as diferenças coloniais, tornando visíveis a variedade de histórias locais escondidas ou suprimidas.

\section{A práxis acadêmica em tempos de globalização e de poder da colonialidade}

É preciso, no entanto, ter claro que a produção desse pensamento de fronteira enfrenta dificuldades adicionais em tempos de globalização. Ao ser percebida como processo, a globalização passa a ser entendida como uma exacerbação da operação das relações hierárquicas sobre um sistema de redes e como a intensificação de trocas. De fato, o fluxo de ideopanoramas também se intensifica com a globalização, trazendo novas questões para as relações entre o global e o local (RIBEIRO, 2002).

No campo das práticas intelectuais, esses tempos de globalização se expressam através da hegemonia de um certo discurso "modernizador" que se institui através da normatização, delimitação e controle do fazer acadêmico em termos de produtividade - medida por indicadores, tais como a quantidade de publicações em certas revistas acadêmicas, especialmente, de circulação internacional (MATO, 2002).

Em nosso contexto, um debate publicado na revista Organização \& Sociedade expressa diferentes posições sobre esse discurso e sobre a relação com o estrangeiro. No primeiro artigo, Carvalho e Vieira (2003, p.186) 
questionam a possibilidade de construções originais: "A produção de conhecimento genuíno, criativo, teórico e original, em detrimento da simples aplicação e teste de conhecimento gerado em outros lugares, requer um tempo diferente daquele da produção em massa". Destacam, ainda, a relação da valorização da quantidade com a reprodução de temas e teorias já legitimadas.

[...] para ganhar tempo, partimos de uma dada leitura da realidade, de uma plataforma conceitual já consensual. Fazemos uso do pensamento dominante porque é mais facilmente aceito, sem precisar de tanto esforço e, principalmente, de tanto tempo para torná-lo legítimo, para fundamentá-lo. Ele já o é pela construção ativa a partir de pólos e pessoas legitimadas no campo e, pela repetição generalizada que construiu o consenso. Assim, a academia, pelas normas que se impôs, está nos conduzindo a sermos fabricantes de uma ciência dócil. (CARVALHO; VIEIRA, 2003, p.186)

Na resposta, Bertero (2003, p.190) pede paciência e - pela analogia com a execução de sinfonias por orquestras européias e brasileiras - dá a entender que, de fato, existe uma qualidade superior no que se realiza no contexto dos países do Norte global. Em sua tréplica, Vieira e Carvalho (2003, p. 180) explicitam mais claramente sua posição quanto à reprodução de padrões alienígenas ao nosso ambiente acadêmico:

Como a maior parte da produção tem sua origem nos EUA, parece natural que eles disseminem no campo normas e valores que serão, por vezes copiadas, por vezes impostas a outras "academias" ao redor do planeta, pelo menos no mundo ocidental. A grande questão é a de saber até que ponto os valores e normas por eles institucionalizadas são as mais adequadas para nós. [...] Não estaremos sempre sujeitos a sermos "uma cópia mal feita"? Obviamente não se defende aqui nenhum tipo de isolacionismo científico. Mas que há espaço para identidade própria e criatividade, estamos seguros.

Cabe retomar a muito conhecida expressão de Roberto Schwarz (1992, p.120) sobre as idéias fora de lugar.

Idéias estão no lugar quando representam abstrações do processo a que se referem, e é uma fatalidade da nossa dependência cultural que estejamos sempre interpretando nossa realidade com sistemas conceituais criados noutra parte, a partir de outros processos sociais.

Retomando o ponto de vista materialista: "a teoria é parte também da realidade, e a sua inserção no processo real é parte do que concretamente ela é". Nesse sentido, as idéias só deixam de estar fora do lugar, "quando se reconstroem a partir das contradições locais". Para isso, não basta apenas conhecer o contexto local, é preciso conhecer também o contexto de origem, "para apreciar a diferença, a qual é uma presença objetiva, ainda que um pouco impalpável em nossa vida ideológica" (SCHWARZ, 1992, p.121). Nesta mesma direção, se encontra o alerta de Dussel (2006, p.491):

Apesar de muitos pesquisadores nos países colonizados se considerarem, orgulhosamente, pensadores críticos (ou avançados), muito raramente reconhecem o quanto são eurocêntricos sem serem europeus. Essa é uma questão crucial, e evitá-la é imperdoável [...] Este é, de fato, um outro ângulo da "conquista". Suas mentes têm sido colonizadas de tal forma que a idéia do "outro" é a imagem espelho da identidade européia ou americana. Esse problema mostra que precisamos trabalhar em uma segunda ordem de crítica.

Outra expressão desses tempos de globalização é a valorização e constituição de redes transnacionais de pesquisa.

Graças a uma maior disponibilidade de diversos tipos de recursos, os atores com capacidade para atuar nos niveis globais não apenas promovem suas próprias representações e orientações da ação através de suas relações bilaterais com atores locais, como também através da promoção de eventos e redes de trabalho entre atores locais de numerosos países que, desse modo, organizam-se em torno das representações dos atores que atuam em nivel global. Assim, os atores que podemos chamar "globais", participam em condições "vantajosas" dos processos transnacionais de produção de 
representações significativas. Isso não necessariamente implica que os atores que podemos chamar de "locais" adotem automaticamente as representações que promovem os atores "globais", mas sim que elaboram suas próprias representações no âmbito dessas relações transnacionais. Desse modo, resulta que as representações que orientam as ações dos atores "locais" se relacionam de maneira significativa, ainda que de formas diversas, com as dos atores "globais". (MATO, 2002, p.9)

Entretanto, existem outras possibilidades no que se refere à construção de redes de trabalho locais/globais, organizando-as em torno de histórias construídas da perspectiva de uma alteridade politicamente enriquecida. Ao fazê-lo, pode-se refratar a modernidade através das lentes da colonialidade e, dessa forma, liberar o potencial para pensar a partir da diferença e na direção da construção de mundos alternativos. Tratar-se-ia, então, de considerar a diferença colonial como um espaço política e epistemologicamente privilegiado (ESCOBAR, 2004).

\section{Para encerrar...}

Uma semana após ter apresentado no encerramento do "Eneo" o texto que se encontra no final deste artigo, recebi a mensagem de divulgação do $\mathrm{n}^{\mathrm{o}} 4$ da revista Organization. Nele encontramos diversos estudos com enfoque latino-americano e introdução de um artigo de Eduardo Ibarra-Colado (2006) intitulado "Organization studies and epistemic coloniality: thinking otherness from the margins". Minha reação imediata foi reenviar essa mensagem para os parceiros de fazer acadêmico com os quais havia compartilhado a idéia e o conteúdo daquela sessão. Minha mensagem ironizava a recepção do tema da colonialidade, insinuando que agora que havia uma publicação em inglês e num periódico legitimado do centro; o tema finalmente estava autorizado no campo dos estudos organizacionais brasileiros. Ironia com gosto amargo! Gosto de subordinação!

Voltando ao texto de Ibarra-Colado (2006, p.468), o autor aborda a história dos estudos organizacionais na América Latina como um fenômeno de falsificação.

Isto significa que o conhecimento organizacional do centro tem sido transferido e traduzido na região de modo a interpretar problemas sem levar em conta considerações políticas. Argumentos puramente técnicos dominam tudo. Dessa perspectiva, não estamos lidando com um problema de troca desigual entre nações, mas com deficiências na concepção organizacional que obstruem o funcionamento produtivo e eficiente dos nossos países.

Tal abordagem difere bastante da que venho desenvolvendo neste artigo, onde tem estado sempre implícita - e em muitos momentos explícita - uma posição contra-hegemônica e libertadora em relação às diversas formas de opressão que fazem parte da modernidade e do seu modo de produção. Contudo, apesar dessa diferença ideológica, é possível dialogar com Ibarra-Colado (2006) quando ele afirma, assim como Carvalho e Vieira (2003) já haviam feito, que os pesquisadores latino-americanos se limitam às teorias e métodos do mainstream, de modo a replicar seus achados em ambientes tropicais, em um processo que pode ser sintetizado pela expressão "internacionalização subordinada." (CARVALHO; GOULART; AMANTINO-DE-ANDRADE, 2005).

Ironicamente, este ciclo se repete nos anos 80, quando análises críticas no campo dos estudos organizacionais despertam interesse na região. Pesquisadores latino-americanos adotaram teorias críticas eurocêntricas que têm sido modeladas nos contextos anglo-saxões, incorporando tópicos e agendas similares às que estimularam as discussões no âmbito internacional. [...] Em síntese, o desenvolvimento dos estudos organizacionais na América Latina pode ser entendido como uma versão distorcida do funcionalismo ou do pensamento crítico do centro.

[...] Para pertencer à "comunidade internacional", você precisa falar a linguagem do centro, empregar seus conceitos, debater suas agendas e se conformar com os estereótipos do "sul 
imperfeito", enquanto mantém um "silêncio educado" sobre as causas reais dos nossos problemas. (IBARRA-COLADO, 2006, p.470-71)

Para descolonizar a pesquisa acadêmica é preciso focalizar aspectos centrais, tais como os modos historicamente estabelecidos de produzir objetos de estudo, limites entre disciplinas, limites entre a academia e outros espaços sociais e práticas de pesquisa que produzem certos tipos de conhecimento, entre outros. É claro que a existência de atitudes colonizadas incide sobre uma maior ocorrência de reconhecimento e de incorporação não-reflexiva das representações desenvolvidas no centro.

Atitude colonizada se refere, aqui, a assumir que as interpretações sobre o que ocorre no centro têm valor universal, ignorando seus contextos institucionais e sociais de origem (BOURDIEU; WACQUANT, 2005). Os textos colonizados são aqueles que não ressaltam suas marcas de lugar, que não oferecem uma reflexão sobre as peculiaridades de seu espaço de enunciação, sobre o contexto institucional e social de produção de suas idéias e sobre como essas condições contextuais as condicionam e as limitam.

É importante reiterar que nesse debate não se colocam referentes em torno do nacionalismo ou do nativismo em suas formulações excludentes. Aliás, é bom lembrar que "nem tudo que é nacional é bom, nem tudo que é estrangeiro é ruim, o que é estrangeiro pode servir de revelador do nacional, e o nacional pode servir de cobertura às piores dependências" (SCHWARZ, 1992, p.115). Além disso, como alerta Ribeiro (2002, p.177), é preciso evitar os dois limites extremos: "se o limite distorcido do universalismo é a arrogância do império colonizando todas as outras perspectivas, o limite distorcido do particularismo é a arrogância de uma perspectiva única que se acredita acima das demais". Portanto, é preciso estar muito atento contra qualquer tipo de essencialismo e, simultaneamente, promover relações plurais, descentradas e democráticas em torno de programas pluriversalistas coletiva e solidariamente construídos. 


\section{Texto apresentado na sessão de encerramento do IV Encontro de Estudos Organizacionais}

\section{Porto Alegre - 6 de junho de 2006}

Em primeiro lugar, quero deixar claro que essas reflexões são pessoais e que os demais participantes da organização ou da comissão científica podem ou não compartilhá-las. Da mesma forma, os convidados com os quais vamos partilhar esse momento têm compromisso apenas com seus próprios textos e idéias.

Há cerca de um ano, alguns de nós começamos a conversar sobre a possibilidade de realizar este "IV Encontro de Estudos Organizacionais", aqui em Porto Alegre. Esse desejo se originava da expectativa de que pudéssemos introduzir algumas mudanças no formato e, principalmente, no conteúdo dos nossos eventos acadêmicos. Evidente, portanto, a origem em uma certa insatisfação com o que vem se constituindo como normal em nosso campo de práticas. Incertos quanto à procedência dessa posição, propusemos a realização de um painel, no último "Enanpad", para debater a realização desse "Eneo". Os debates - posteriores à problematização feita a partir de um texto lido na abertura do painel por Marcelo Milano Falcão Vieira, bem como a partir das apresentações feitas por Ana Paula Paes de Paula, José Henrique Faria e Miguel Imas (da Kingston University) - levaram à clara constatação de que nossas inquietações originais eram amplamente compartilhadas pelos presentes.

Como uma decorrência, esse evento foi realizado a partir de uma chamada de trabalhos orientada por um tema direcionador, inspirado de modo não literal em Guerreiro Ramos e identificado pela frase apropriando teoria e prática, deslocando o centro. É especificamente sobre esse aspecto que realizamos essa reflexão.

A decisão de adotar o tema direcionador não foi fácil nem impensada. Havia temor de que não houvesse número suficiente de trabalhos, já que a prática tem sido a de que nossos eventos sejam mostras do que estamos produzindo. Não temos a cultura de responder a chamadas com produtos novos e direcionados. Esse pode ser um desafio para nossa comunidade de estudiosos de organizações, caso haja a decisão dos próximos organizadores de dar continuidade a essa trajetória que apenas começamos a experimentar. Caso isso ocorra, poderíamos ter cenários complementares - o "Enanpad", como uma grande mostra do que se produz no nosso campo acadêmico, e o "Eneo", como espaço para construção de acúmulos em torno de temas que se refiram às necessidades do nosso contexto sociohistórico.

Os acontecimentos não surpreenderam quanto à expectativa de que a maioria dos trabalhos seguisse o hábito de enviar para avaliação o que está disponível. Não devemos nos iludir, o procedimento não foi diferente dessa vez. Até porque, para que possa ser de outra forma, é preciso divulgar com maior antecedência o tema orientador. No entanto, não há qualquer dúvida de que um conjunto expressivo de trabalhos se vinculou efetivamente ao tema, enquanto um conjunto também expressivo evidenciou um esforço de adaptação ao tema. Os anais e as apresentações realizadas comprovam essa constatação.

Como um registro dos trabalhos que se vincularam expressamente ao tema e, mais que isso, buscaram inspiração em alguns intérpretes do Brasil (expressão usada pelo prof. Sérgio Alves no painel realizado no "Enanpad"), convido alguns autores para participar desse diálogo e dessa reflexão.

Em “A antropologia de Guerreiro Ramos”, Ariston Azevedo e Renata Ovenhausen Albernaz destacam a preocupação do nosso sociólogo com a possibilidade de adquirir consciência crítica, em nível coletivo, como condição para o processo de emancipação humana. Assim, a atitude parentética seria um caminho para a autonomia dos sujeitos e, mais que isso, um apoio para, como acadêmicos, superarmos as abordagens que obstaculizam, em vez de potencializar, esse caminho. Através da atitude parentética poderíamos romper com a patologia da conformidade social. Além disso, ao incorporarmos a categoria do conflito e deixarmos de lado a ênfase sistêmica no equilíbrio social, estaríamos autorizados a considerar como legítimas a resistência à conformidade e a luta pela criação de novas formas sociais, de novos espaços relacionais para o exercício da existência autêntica. Para que houvesse uma articulação teórica sistemática, capaz de perceber os códigos de ética institucionalizados na sociedade pós-industrial como truques ou fachadas abertos ao questionamento, Guerreiro Ramos propõe o modelo do homem parentético - um ser de razão substantiva ou noética, capaz de transcender ao mundo em que está posto. 
Em "Uma abordagem ao desenvolvimento local inspirada em Celso Furtado e Milton Santos", Sueli Goulart visita esses autores em busca de alternativas de compreensão para o fenômeno do pólo de tecnologia de informação e comunicação de Pernambuco, em sua relação com o desenvolvimento. Desse encontro, resulta a retomada de temas esquecidos, como o das especificidades das formações sociais do capitalismo periférico e o da produção do território como resultante de relações de poder. Há um importante indicativo nesse artigo: a potência explicativa de teorias produzidas por autores que teorizaram a partir dos seus contextos de referência e para analisar fenômenos que se efetivaram nesses mesmos contextos.

Em "O poder do bacharel no espaço organizacional brasileiro", Breno de Paula Andrade Cruz e Paulo Emílio M. Martins partem de uma constatação crítica sobre a contenção do pensamento sobre as organizações em uma prisão epistemológica de viés funcionalista. Resgatando a natureza social do fenômeno administrativo e sua condição de fato político, histórico e cultural, os autores buscam inspirações em dois clássicos: Raízes do Brasil, de Sérgio Buarque de Holanda, e Sobrados e mucambos, de Gilberto Freyre. Com referência nesses registros e adotando a perspectiva do poder condicionado - onde a mudança de uma convicção leva o indivíduo a se submeter à vontade alheia - e a do poder como conflito, surge o tema da inferiorização, marcada pela utilização de linguagens herméticas, pela capacidade de gerar um sentimento de inferioridade no outro e de mostrar-se inteligente e ousado. Com a introdução da categoria de capital social simbólico, a partir de Pierre Bourdieu, os autores podem, então, avançar seu argumento na direção da valorização do bacharelismo como capital dos poderosos e da vocação para uma sociedade de diferentes como aspectos marcantes da formação social do Brasil. Nas partes finais do artigo, fica clara a riqueza da trajetória nele realizada, com o resgate da historicidade do fenômeno do poder nas organizações brasileiras e a correspondente e tão necessária valorização das peculiaridades do campo organizacional brasileiro.

Voltando a Guerreiro Ramos, nosso evidente inspirador na proposição do tema, quero recuperar a crítica, por ele feita, à participação das ciências sociais na má compreensão da questão racial. Em um texto chamado "Introdução crítica à sociologia brasileira", ele se refere ao caráter importado da reflexão sociológica brasileira, usando o termo pseudomorfose para designar uma formação falsa, desconectada da realidade e dos problemas sociais nacionais, além de engessada por conceitos metodológicos eleitos como ortodoxia invariavelmente estrangeira. Ali se encontra a defesa da emancipação da produção acadêmica brasileira da alienação patológica a que está submetida (no caso, tratando especificamente da sociologia do negro) e que passaria, necessariamente, pela ruptura com o pressuposto universalizante inerente ao nosso discurso acadêmico.

Em tempos mais recentes, Bourdieu denuncia a importação mimética, não reflexiva, de categorias de análise sociológica transplantadas de contextos históricos distintos e aplicadas automaticamente a realidades diferentes. Diz ele, em co-autoria com Wacquant - o imperialismo cultural repousa no poder de universalizar os particularismos associados a uma tradição singular qualquer, tornado-os irreconhecíveis como tais.

No contexto latino-americano, há pelo menos uma década, ocorre uma intensa produção em torno do tema da colonialidade do saber, conseqüência da colonialidade do poder. Uma das expressões da colonialidade do poder é a relação paradoxal entre a reivindicação de uma matriz cultural nacional e ter o centro como modelo, assumindo uma posição periférica ao que é legitimado como representação da civilização. Ser da periferia é ter o centro como modelo, é assumir uma inserção colonial no sistema mundo, é viver uma sensação de desterro como intelectuais. Como afirma Roberto Schwarz, para dentro essa sensação se expressa através do uso espúrio ou desfocado de idéias importadas como um imperativo de civilização, perfeitamente adaptado ao nosso ambiente de colonialidade.

Essas são apenas notas para reflexão, sem qualquer pretensão de conclusão ou de encerramento. Uma nota importante para essa reflexão é, certamente, o quanto podemos encontrar em termos de aprendizagem, inspiração e potência, quando visitamos autores que se preocuparam em perceber e explicar a nós mesmos, em pensar sobre o futuro que podemos ter - ou não. Para encerrar, já que é preciso, deixo no ar as palavras de Darcy Ribeiro, de seu livro $O s$ brasileiros: teoria do Brasil. Diz ele que "falta uma teoria capaz de dar conta da nossa realidade, da nossa formação sociocultural" - e que nosso desafio é, entre outros, "como estabelecer a forma e o papel da nossa cultura erudita em sua relação com a criatividade popular, mesclando as tradições mais díspares para compreender nossa versão do mundo e de nós mesmos!" 


\section{Referências}

BERTERO, 0. Comentando idéias em debate. Organização \& Sociedade, v.10, n.26, p.190- 191, 2003.

BOURDIEU, P.; WACQUANT, L. A astúcia da razão imperialista. In: WACQUANT, L. (Org.). 0 mistério do ministério: Pierre Bourdieu e a política democrática. Rio de Janeiro: Revan, 2005. p.209-230.

CARVALHO, C. A.; GOULART, S.; AM ANTINO-DE-ANDRADE, J. Internacionalização subordinada: é possível subverter as regras do jogo! In: Anais do ENANPAD, Área Gestão das Organizações e Desenvolvimento, 2005.

; VIEIRA, M. M. F. Algo está podre no reino da Dinamarca. Organização \& Sociedade, v.10, n.26, p.185- 187, 2003.

DERRIDA, J. A escritura e a diferença. São Paulo: Perspectiva, 1971.

. Espectros de Marx: o estado da dívida, o trabalho e a nova Internacional. Rio de Janeiro: Relume Dumará, 1994.

Points: interviews - 1974-1994. Stanford: Stanford University Press, 1995.

DUSSEL, E. Philosophy in Latin America in the twentieth century: problems and currents. Disponível em: $<$ <ttp://168.96.200.17/ar/libros/dussel/artics/filo.pdf>.

. Europa, modernidad y eurocentrismo. In: LANDER, E. (Org.). La colonialidad del saber: eurocentrismo y ciencias sociales. Buenos Aires: Clacso, 2000. p.246-255

Ética da libertação na idade da globalização e da exclusão. Petrópolis: Vozes, 2002.

Globalization, organization and ethics of liberation. Organization, v.13, n.4, p.489-508, 2006.

ESCOBAR, A. "Words and knowledge otherwise": the Latin American modernity/coloniality research program. In: CEISAL. Cruzando fronteras en America Latina. Amsterdan: Cedla, 2002.

Beyond the third world: imperial globality, global coloniality and anti-globalisation social movements. Third World Quarterly, v.25, n.1, p.207-230, 2004.

GUERREIRO RAMOS, A. Introdução crítica à sociologia brasileira. Rio de Janeiro: Editora da UFRJ, 1995.

IBARRA-COLADO, E. Organization studies and epistemic coloniality: thinking otherness from the margin. Organization, v.13, n.4, p.463$488,2006$.

MALDONADO-TORRES, N. The topology of being and the geopolitics of knowledge: modernity, empire, coloniality. City, v.8, n.1, p.29-56, 2004.

MATO, D. Estudios y otras prácticas intelectuales latinoamericanas en cultura y poder. Caracas: Clacso, 2002.

MIGNOLO, W. The geopolitics of knowledge and the social difference. Disponível em: <http://multitudes.samizdat.net//The geopolitics- ofknowledge- and.html>. Acesso em set. 2001.

. Os esplendores e as misérias da "ciência": colonialidade, geopolítica do conhecimento e pluriversalidade epistêmica. In: SANTOS, B. S. (Ed.). Conhecimento prudente para uma vida decente. Revisitado. Porto: Edições Afrontamento, 2003.

MIRANDA, J. B. A questão da desconstrução em Jacques Derrida: contribuição para a análise do método na modernidade. In: BABO, M. A. (Org.). Textualidades. Lisboa: [s.n.], 1986.

NASCIMENTO, E. Derrida. Rio de Janeiro: Jorge Zahar, 2004.

QUIJANO, A. Colonialidad y modernidad-racionalidad. In: BONILLA, H. (Ed.). Los conquistados: 1492 y la población indígena de las Américas. Quito: Flacso-Tercer Mundo, 1992.

. José Carlos Mariátegui y Europa: el otro lado del descubrimiento. Lima: Empresa Editora Amauta, 1993.

RIBEIRO, D. 0 povo brasileiro. São Paulo: Companhia das Letras, 2006. 
RIBEIRO, G. L. Post-imperialism: para una discusión después del post-colonialismo y multiculturalismo. In: MATO, D. Estudios y otras prácticas intelectuales latinoamericanas en cultura y poder. Caracas: Clacso, 2002. p.161-181.

SARAMAGO, L. Hermenêutica e desconstrução: por uma ética da leitura. In: DUQUE- ESTRADA, P. C. (Org.). Desconstrução e ética: ecos de Jacques Derrida. Rio de Janeiro: Editora PUC; Edições Loyola, 2004. p.65- 78.

SCHWARZ, R. Que horas são? São Paulo: Companhia das Letras, 1987.

. O pai de família e outros estudos. São Paulo: Paz e Terra, 1992.

SEGRERA, F. L. Abrir, impensar y redimensionar las ciencias sociales en America Latina y el Caribe: es posible uma ciencia social no eurocéntria em nuestra región. In: LANDER, E. (Org.). La colonialidad del saber: eurocentrismo y ciencias sociales. Buenos Aires: Clacso, 2000. p.177-199.

TEVES, R. P. El lugar de la utopía: aportes de Aníbal Quijano sobre cultura y poder. In: MATO, D. (Coord.). Estudios y otras prácticas intelectuales latinoamericanas en cultura y poder. Caracas: Clacso, 2002. p.225- 234.

VIEIRA, M. M. F.; CARVALHO, C. A. Tréplica ao professor Bertero. Organização \& Sociedade, v.10, n.27, p.179- 180, 2003. 